Логосемная и коммуникемная структура

художественного текста малого жанра

(на материале короткого рассказа В. Борхерта

“Nachts schlafen die Ratten doch” («Ведь ночью крысы спят»))

Макаренко А. С.

\begin{abstract}
Аннотация. Цель исследования - выявить внутреннюю семантическую структуру художественных текстов малого жанра, а также способы смыслопорождения. В данной статье проводится морфотемный анализ художественного текста малого жанра В. Борхерта "Nachts schlafen die Ratten doch" («Ведь ночью крысы спят»), который посвящен теме войны. Научная новизна заключается в построении вертикальных синтагмем как связующих звеньев текстемных блоков с целью выявления в художественном тексте глубоких коммуникативных смыслов. В результате на базе когитологической концепции были выявлены неявные скрытые смыслы, заложенные автором, а также логико-семантические блоки задействованных в данном тексте лингвем.
\end{abstract}

\title{
EN Logosemic and Communicemic Structure of a Small Genre Literary Text (by the Material of W. Borchert's Short Story "Nachts schlafen die Ratten doch" (“Rats Do Sleep at Night”))
}

Makarenko A. S.

\begin{abstract}
The study aims to identify the internal semantic structure of small genre literary texts, as well as ways of meaning generation. The paper carries out a morphothemic analysis of the small genre literary text "Nachts schlafen die Ratten doch" ("Rats Do Sleep at Night”) by W. Borchert, which addresses the topic of war. Scientific novelty lies in constructing vertical syntagmemes as connecting links of texteme blocks in order to identify deep communicative meanings in the literary text. As a result, on the basis of the cogitology concept, implicit hidden meanings given by the author, as well as logical and semantic blocks of the linguemes involved in the text have been identified.
\end{abstract}

\section{Введение}

Актуальность исследования обусловлена необходимостью применения когитологической концепции к анализу художественных текстов малого жанра с коммуникативной точки зрения.

Несмотря на достаточное количество научных трудов в отечественной и зарубежной лингвистике, в которых раскрывается специфика художественных текстов, недостаточно полно описана когитологическая концепция для анализа художественных текстов малого жанра. В когитологии как науке о языкосознании и речемышлении используется модель морфотемного анализа.

Задачи, решаемые в рамках настоящего исследования:

- проанализировать логосемы лингвемного состава текста;

- представить линейные и вертикальные синтагмемы как связующие звенья текстемных блоков;

- определить факторы формирования глубокого коммуникативного смысла текста.

В статье применяются следующие методы исследования: морфотемный анализ, дефинитивный и компонентный анализ - для выявления понятийных признаков концепта.

Теоретической базой исследования послужили труды Л. Г. Бабенко, Ю. В. Казарина (2004), В. П. Белянина (2020), В. А. Пищальниковой (1991), которые особое внимание уделяли понятиям «текст» и «художественный текст». Существует множество определений художественного текста. Это связано с тем, что понятие 
«текст» не может быть объяснено исключительно лингвистическим путем. Он может представлять собой набор определенных знаков, порождение знаков коммуникантом и восприятие его реципиентом, продукт знаковой деятельности коммуниканта и реципиента (Бабенко, Казарин, 2004, с. 27). В. А. Пищальникова (1991, с. 3) в своем определении акцентирует внимание на коммуникативной природе текста. Она определяет художественный текст как коммуникативно направленное вербальное произведение, которое обладает эстетической ценностью, выявленной в процессе восприятия этого текста. В. П. Белянин (2020) рассматривает художественный текст как личностную авторскую интерпретацию действительности. Интерпретируемость в качестве универсального свойства текста описывают в своих научных работах Л. Н. Мурзин, А. С. Штерн (1991), В. 3. Демьянков (2005), И. В. Третьякова (2002). Они подчеркивают, что художественный текст наиболее интерпретируем, так как при прочтении реципиент привносит в текст собственные представления о тех или иных событиях, свое отношение к происходящему. Понимание художественного текста требует выхода за пределы буквального прочтения и может быть определено как истолкование текста путем соотношения с другими текстами и культурным контекстом (Третьякова, 2002, с. 39).

Л. Н. Мурзин и А. С. Штерн (1991, с. 25) в своей работе «Текст и его восприятие» выделяют в тексте глубинный (семантический) и поверхностный (лексико-грамматический) уровни. На глубинном уровне текст расчленен для выделения в нем тех или иных признаков. Семантический уровень текста структурен, в его состав входит некая цепочка компонентов как результат расчленения единого объекта описания. На поверхностном уровне текст непрерывен. По этой причине его следует воспринимать целостно. И. Р. Гальперин (2009) подробно описывает части текста и способы связи между его составными частями. По-прежнему не раскрытым, но актуальным остается вопрос о способах смыслопорождения.

В решении вопроса о способах смыслопорождения интерес представляют интегративные процессы языка и сознания, речи и мышления, а также соотношение языкового и мыслительного материала. Данный вопрос может быть решен с помощью применения основополагающих принципов морфотемного анализа путем выявления универсальной структуры текста, который предлагает в своих работах А. И. Фефилов (2006, с. 112). Речь идет о формантно-семантической структуре. Тема состоит не только из поверхностной семантики, но и из синтагмемы (глубинной семантики). Морфотема как операционная модель основных единиц языкосознания и речемышления (лингвемы и локутемы) используется в исследованиях когитологической направленности. Лингвема - это языкослово, а локутема - речеслово. Когитология является особым ответвлением от когнитивной лингвистики. Она ориентирована на языковое сознание и речевое мышление. Морфотемный анализ способствует определению закономерностей смыслопорождения и интерпретации текста.

Практическая значимость исследования заключается в том, что его материалы могут быть использованы в вузах гуманитарного направления при изучении дополнительных курсов по следующим дисциплинам: «Введение в языкознание», «Теоретические основы лингвистики», «Сравнительное языкознание». Полученные данные могут быть применены при детальном рассмотрении текстов других жанров для выявления глубокого смысла не только в коммуникативном аспекте. Это также может способствовать более детальному обоснованию теоретических основ когнитивной лингвистики и когитологии.

\section{Основная часть}

Картина мира в сознании человека отражает отношение человека к человеку, к предметам окружающей его действительности, к межпредметному взаимодействию и межчеловеческим отношениям. Это и есть мыслительные каналы восприятия. Указанные отношения укладываются в сферу взаимодействия логикомыслительных категорий: субстанциональности, реляциональности, локальности, квалитативности, темпоральности и квантитативности (Фефилов, 2018, с. 86). Классы логико-мыслительных понятий вступают в определенные отношения между собой, тем самым формируя концептуальную парадигму. Концептуальной парадигмой принято считать систему опорных элементов форм мышления, по принадлежности к которым распределяются все мыслительные понятия как социально обусловленные образы объективной действительности в сознании человека (Фефилов, 2017, с. 91). Комбинация нескольких логико-мыслительных компонентов представляет собой простую концептему (структуру мысли, организацию мыслительных понятий). Пример концептемы: юноша («человек мужского пола в периоде юности»). На уровне языка концепту соответствует логосема (логико-семантический признак). Совокупность логосем, образующих линейную, синтагмообразную структуру, называется синтагмемой. Это прообраз концептемы (Фефилов, 2018, с. 96), ср. юноша - (1) «тот, кто» (Одушевленная субстантность - Суб Одуш) - (2) «является» (Экзистенциальный релятор - Рел Экзист) (3) «юным, молодым» (Квалитативность - Квал). При этом один из признаков синтагмемы получает явную выраженность на номинационно-семантическом уровне (в виде мотивированной номемы). Пример логосемы: писатель - (1) «тот, кто» (Суб Одуш) - (2) «пишет» (Рел). Пример синтагмемы: мебельщик - (1) «тот, кто» (Суб Одуш) - (2) «изготавливает» (Рел) - (3) «мебель» (Суб Неодуш) (примеры составлены автором статьи. - A. M.).

Содержательные признаки синтагмемы принято называть контенсионалом. Контенсиональные признаки «ответственны» за содержательное наполнение синтагмемных компонентов. Например, в слове «мебельщик» контенсионал присутствует дважды: в номинационном признаке «мебель» (= «предметы комнатной обстановки (столы, стулья, диваны и т.п.)») и в целостной базовой номинации «мебельщик» (= «мастер, изготавливающий мебель»). 
Для примера проанализируем короткий рассказ известного немецкого писателя В. Борхерта (Borchert, 2018) “Nachts schlafen die Ratten doch” («Ведь ночью крысы спят»). Прежде чем обратиться к идейному содержанию текста, следует провести анализ логосем лингвемного состава текста с целью выявления логико-семантических блоков задействованных в данном тексте лингвем. Логико-семантические блоки подразделяются с учетом проминентности на субстанциональный, локальный, темпоральный, реляциональный, квалитативный и квантитативный блоки.

1. Субстанциальный блок: Jürgen (Юрген), der Mann (мужчина), die Kaninchen (кролики), der Bruder (брат), die Ratten (крысы), der Lehrer (учитель), der Vater (отец) (одушевленные); das Messer (нож), der Korb (корзина), der Stock (палка), Kaninchenfutter (кроличий корм), die Pfeife (трубка), die Bотbе (бомба) (неодушевленные).

2. Локальный блок: Die Schuttwüste (мусорная пустыня), vor ihm (перед ним), zwischen ihnen (между ними), in der Hand (в руках), hoch (выше), hier (здесь), im Korb (в корзине), ins Haus (в дом), unten (внизу), da (там), Kиһlen in den Schutt (ямки в мусоре), der Kaninchenstall (загон для кроликов), innеn (внутри), пеbеn (рядом), iт Keller (в подвале), ӥber die Mauerreste (через остатки стен).

3. Темпоральный блок:

- план ближайшего прошлого (для героев - наступившее сегодня): immerzu (все время), immer (всегда), nachts (по ночам), seit Sonnabend (с субботы);

- план близкого прошлого (для героев это план грядущего завтра по отношению к прошедшему сегодня): wenn es dunkel wird (когда стемнеет);

- план отдаленного прошлого: jetzt (сейчас), warten (дожидаться).

4. Реляциональный блок:

- акционального типа: реальные действия: flimmerte (мерцало), döste (дремала), hatte... zи (закрыл), теrkte (заметил), sie haben mich (поймали), dachte (подумал), blinzelte (пригляделся), sah (увидел), riskierte (рискнул), erkannte (узнал), schlafe nicht (не сплю), aufpassen (сторожить), nickte (кивнул), hielt... fest (сжал), setzte... ab (поставил), wischte (вытер), verwundert (удивился), fragte (спросил), lag (лежала), rauchst (куришь), drehe (делаю самокрутки), еssen (едят), раst... auf (следишь), zеigte (показал), sagte leise (прошептал), тасhtе (сделал), dachte (думал), futtere (покормлю), willst (хочешь), rief (крикнул), sah (видел);

- ирреальные действия: konnte (мог бы);

- реальная модальность: schläfst hier wohl (должно быть спишь);

- посессивного типа (обладание): an seinem (в его), unser (наш);

- трансмотивного типа (передвижение): gekommen war (подошел), stand (стоял), stiess (nнул), gehst nicht (не ходишь), lief (бежал);

- локального типа: bleiben (остаться);

- темпорального типа: war (был), wurde (стало), wenn es dunkel wird (когда стемнеет), warte (жду), essen (eсmь), warten (подождать).

5. Квалитативный блок:

- субстанционального типа: leise (тихий), krummen (искривленные), älteren (пожилого), gross (большая), fixer (расторопный), kleine (маленькие), rot (красный), grüп (зеленый), grau (серый), wеiß (белые);

- реляционального типа: oben (свыше), leise (тихо), mit einmal (внезапно).

6. Квантитативный блок:

- субстанционального типа: пеun (девять), siebenundzwanzig (двадцать семь), vier (четыре);

- реляционального типа: hin und her (туда-сюда).

Представим вертикальные связи лингвем, взаимосвязанных через реляторы.

$\begin{array}{ll}\text { Суб Одуш } & \text { - der Mann (мужчина) } \\ \text { Реляциональность } & - \text { wischte (вытер) } \\ \text { Суб Неодуш } & - \text { das Messer (нож) } \\ \text { Суб Одуш } & \text { - Jürgen (Юрген) } \\ \text { Реляциональность } & - \text { sagte (сказал) } \\ \text { Квалитативность } & \text { - verächtlich (пренебрежительно) } \\ \text { Суб Одуш } & \text { - Die Ratten (крысы) } \\ \text { Реляциональность } & - \text { schlafen }(\text { спят) } \\ \text { Темпоральность } & - \text { nachts }(\text { по ночам) }\end{array}$

Когда реципиент читает текст, то в первую очередь видит слова, которые затем образуют словосочетания, словосочетания же образуют предложения. Это горизонтальное прочтение текста. Читая текст линейно, читатель может лишь ознакомиться с буквальным смыслом текста и не всегда понимает его глубокий коммуникативный смысл и замысел автора. При более детальном прочтении текста можно заметить, что, например, слово из первого предложения коррелирует со словом из десятого предложения. Для того, чтобы установить дистантные условно «вертикальные» связи между языковыми единицами, не связанными непосредственно, нужно выявить морфотемную структуру данного текста или текстему (концептуально-когниционную структуру текста в коммуникативном дискурсе). Это позволит реципиенту понять заложенный автором текста глубокий коммуникативный смысл. Коммуникативный смысл обусловлен знанием пресуппозиций, намерением автора. Он чаще всего скрывается в иносказательных высказываниях. Глубокий коммуникативный смысл требует от реципиента большого интеллектуального напряжения. Он связан не только со знанием явно повествуемой, 
излагаемой ситуации, но и с экстралингвистическими знаниями (культурно-историческими, политическими, экономическими). Коммуникативные смыслы формируются на основе указанных блоков логосем.

Текстему образует объединение пропозитем (семантическая основа предложения) как прототипов комплексных синтагмем в компактные или рассеянные блоки. Для художественных текстов характерна рассеянная (разбросанная) текстема. В свою очередь, блоки выделяются по преимуществу репрезентируемого концепта или по логосемным признакам и по приоритету тематического контенсионально-когниционного наполнения (Фефилов, 2018, с. 128). Под термином «когниция» принято понимать знания, основанные на какой-либо информации; содержательное наполнение концепта; то, о чем говорится. Коммуникативные смыслы строятся на когниции, а когниция входит в объем концепта. В художественных текстах лингвемная и локутемная структура формируется в зависимости от коммуникативно-прагматических установок автора. В рассеянной текстеме логосемы, контенсионализированные определенными когнициями, объединяются в логосемные блоки «по вертикали» посредством как неявных, имплицитных смысловых, так и явных, промежуточных реляторов, обычно глагольно-предикатного типа. В таком типе текстемы когниции не лежат на поверхности. Они скрыты. Тематические реляции текстемы складываются в процессе написания текста, и реципиент осознает их только лишь при чтении (с. 132).

Теперь нужно представить смысловой, тематический анализ локутемного состава текста с целью описания тематических, повествовательных каналов, которые представлены лингвемами. Лингвемы, в свою очередь, объединяются в контактные линейные пропозициональные связи и вступают в дистантные вертикальные отношения для выражения ситуаций. В анализируемом тексте основным каналом является субстанциональный канал. Темпоральный, локальный и реляциональный каналы также могут быть задействованы, но они несамостоятельны. Повествовательные каналы субстанционального блока требуют более детального рассмотрения.

Прежде всего представим одушевленную, персонифицированную субстанциональность: Jürgen (Юрген), der Mann (мужчина), die Kaninchen (кролики), der Bruder (брат), die Ratten (крысы), der Lehrer (учитель), der Vater (отец).

Представим эпюру, в которой обозначим реляции между указанными одушевленными субстанциями (см. Рисунок 1).

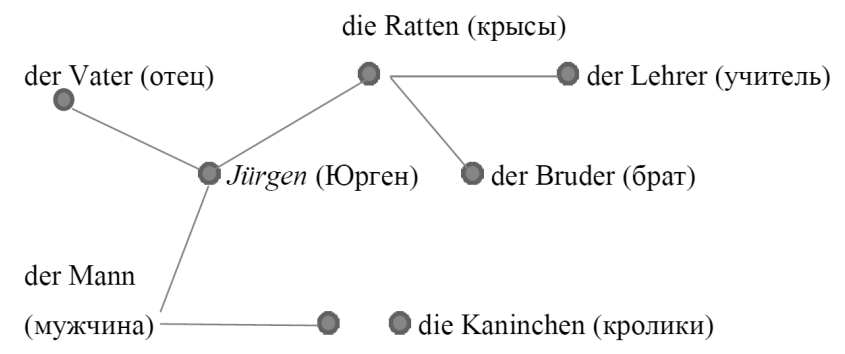

Рисунок 1. Реляции персонифицированной субстанциональности

Теперь обозначим неодушевленную, сопутствующую субстанциональность: das Messer (нож), der Korb (корзина), der Stock (палка), das Kaninchenfutter (кроличий корм), die Pfeife (трубка), die Вотье (бомба).

Читатель узнает, что протагониста рассказа зовут Юрген. Ему девять лет. Он встречает мужчину. В руках у Юргена была большая палка, которой он отпугивал крыс. Юрген сторожил мертвое тело своего младшего брата. Юрген сторожил тело всегда - и по ночам тоже. На вопросы мужчины он отвечал мужественно. Под одним из камней мальчик хранил половинку батона и стальную коробку. Юрген делал самокрутки. В дом Юргена попала бомба. У Юргена были учитель и отец. В мусоре Юрген делал маленькие ямки - кроватки. Юрген хотел взять у мужчины белого кролика. Он сообщает мужчине, что дома у него есть доски от ящика для сооружения загона для кроликов. Юрген остался ждать мужчину. О мужчине сообщается то, что он пожилой. У него кривые ноги. Имя мужчины неизвестно. В руках он нес нож и корзину, в которой нес корм для кроликов. Он называет мальчика расторопным малым. У него было двадцать семь кроликов, по окрасу - белые, серые, бело-серые. Мужчина интересовался у мальчика, что он сторожит. Он предполагал, что мальчик сторожит деньги. Он предлагает мальчику посмотреть кроликов. Мужчина спрашивал у мальчика, курит ли он и есть ли у него трубка. Мужчина хотел подарить мальчику одного кролика. Он говорит мальчику, что крысы по ночам спят и что он может спокойно идти домой. Мужчина сказал мальчику, чтобы он ждал его, пока он кормит кроликов, чтобы отвести его домой и подарить ему одного маленького кролика. Он считает, что человек, который не знает, что крысы ночью спят, не должен быть учителем. Мужчина хотел показать отцу мальчика, как построить загон для кроликов. Он ушел на своих кривых ногах с корзиной, внутри которой лежал зеленый корм для кроликов.

Очень важными являются повествовательные ветви брат, отец и учитель главного героя. О брате реципиент знает лишь то, что он младше протагониста. Ему было четыре года. Он исчез в подвале, когда в дом попала бомба. Об учителе известно только, что это он сказал мальчику, что крысы ночью не спят, они питаются мертвецами, людьми. Отец в тексте упоминается однажды. Автор лишь осведомляет читателя о том, что у протагониста есть отец.

Рассказ В. Борхерта был написан в послевоенное время по большей части в форме диалога. Коммуникативные смыслы вычитываются реципиентом в данном тексте из диалога. В диалоге возникают коммуникемы. 
Под коммуникемой принято понимать коммуникативный признак речи, который наслаивается на локутему в процессе ее формирования, а также содержание локутемно-концептемного единства (Фефилов, 2010, с. 191). Интенсиональный (фиксация наличия предмета), иллокутивный (предостережение), перлокутивный (руководство к действию, рекомендация) признаки представляют собой разновидности коммуникемы. С коммуникемой совмещается когниция. Рассмотрим пример из текста: “Bist ja ein fixer Kerl”. / «Pacmoponный малый». Сообщается, что речь идет о ребенке. Реципиент осознает, что есть кто-то, кто акцентирует внимание на том, что это именно не взрослый человек. Этот же человек констатирует, что ребенок расторопный, то есть сообразительный, догадливый. «Расторопный» является информативной когницией. Текст написан в форме диалога, с помощью которого передаются настроение и чувства, переживания героев. Благодаря мастерству автора реципиент улавливает внутренний смысл беседы мальчика и мужчины, то, что не названо, но является важным в жизни героев. В форме диалога воспроизводятся мысли героев, их мировоззрение. Само слово “der Krieg” («война») в тексте не употреблено ни разу. При этом реципиенту очевидно, что действие описывается в годы войны. На это указывают квалитативные характеристики: “Staubgewölke” («облака пыли»), “noch dunkler” («еще темнее»), “dunkel” («темный»), “leise” («тихий»), “die zusammengesackten Mauern” («сложившиеся стены»); локальные характеристики: “Schuttwüste” («мусорная пустыня»), “Unser Haus kriegte eine Bombe” («В дом попала бомба»).

Пожилому мужчине автор приписывает такие квалитативные характеристики, как доброта, сочувствие и ответственность. Доброта проявляется в неравнодушии мужчины к судьбе мальчика. Он не прошел мимо. Представим синтагмемы линейных предложений, тем самым демонстрируя контактные связи (см. Рисунок 2).

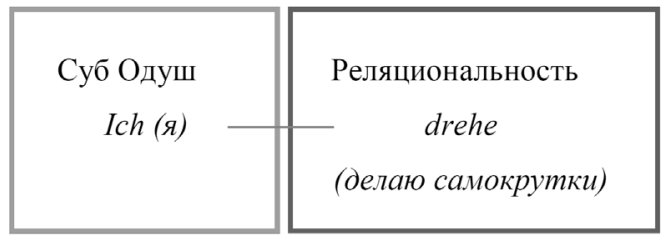

Рисунок 2. Синтагмема линейного предложения

Из данной синтагмемы можно сделать вывод, что мальчик курит. Мужчине жаль, что мальчик курит. Доброта также проявляется и в его отношении к своим кроликам. В такое непростое время мужчина не забывает кормить своих кроликов, добывать для них корм. Такой смысл можно вывести из следующей вертикальной синтагмемы (см. Рисунок 3).

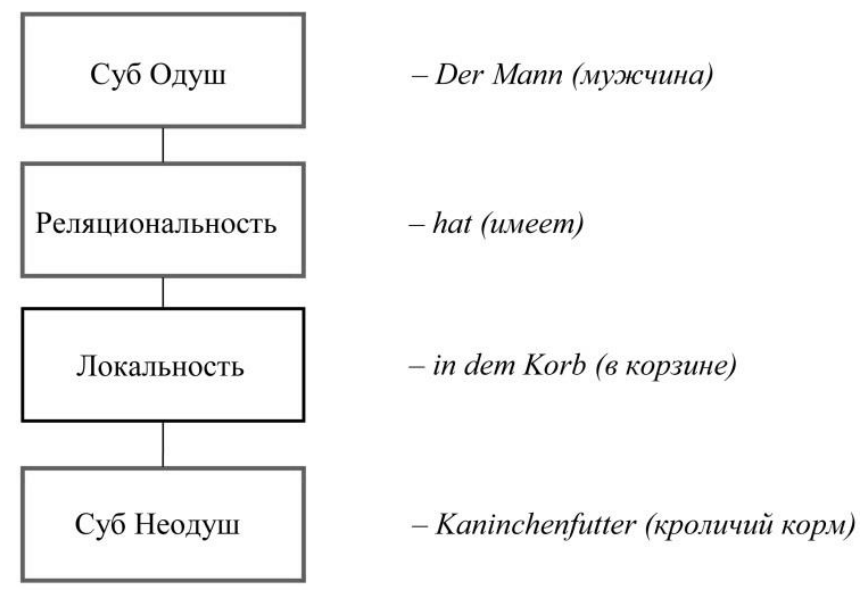

Рисунок 3. Синтагмема вертикальных отношений

Ответственность проявляется в желании мужчины забрать мальчика, отвести его домой, не бросить на произвол судьбы. Маленький мальчик вызывает сочувствие у пожилого мужчины. В начале беседы с незнакомым мужчиной мальчик зажат, он остерегается и недоверчив: “fasste seinen Stock fest an” («еще крепче вцепился в палку»), “sagte verächtlich” («сказал пренебрежительно») (см. Рисунок 4).

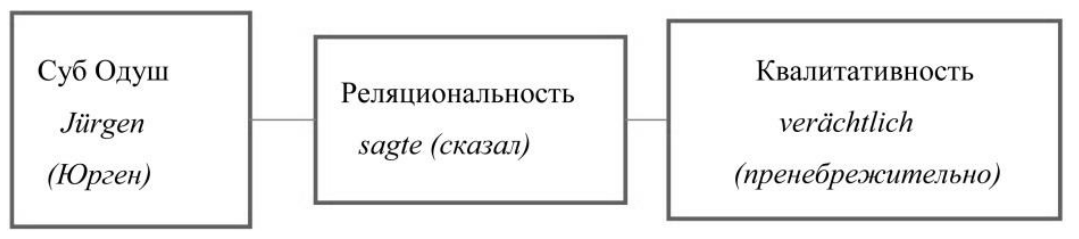

Рисунок 4. Линейная синтагмема

Но позже он начинает открываться незнакомцу, он начинает ему верить. Он больше не верит словам учителя, что крысы ночью не спят, он начинает верить словам незнакомца (см. Рисунок 5). 


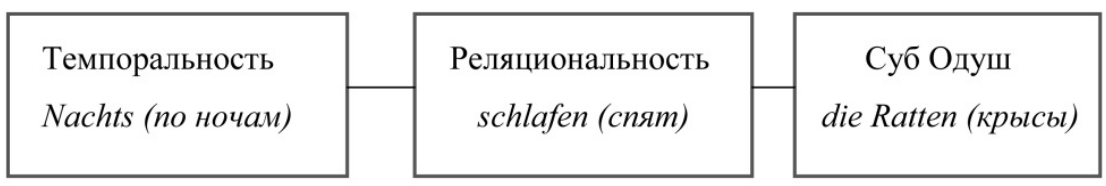

Рисунок 5. Синтагмема линейного предложения

На этом этапе реципиент понимает, что повествование строится именно на этом качестве мужчины лжи. Мужчина солгал мальчику с намерением уговорить его пойти домой и продолжать жить нормальной жизнью. Это качество не выражено автором отдельной лингвемой, но его без труда реципиент вычитывает из текста. Стоит заметить, что, казалось бы, ложь принято считать отрицательным качеством, но в тексте оно показано как положительное.

Помимо коммуникативных смыслов в тексте обнаруживаются и другие, более глубокие смыслы. С коммуникативными смыслами пересекаются прагмемные смыслы. Прагмема выполняет иллокутивную функцию и акцентирует чаще скрытую цель высказывания, сообщения, оценки событий, намерения, установки автора или героев. Прагмема входит в коммуникему как особое наслоение (Фефилов, 2018, с. 140).

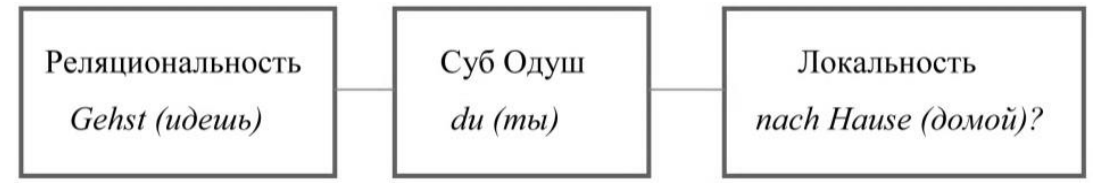

Рисунок 6. Линейная синтагмема

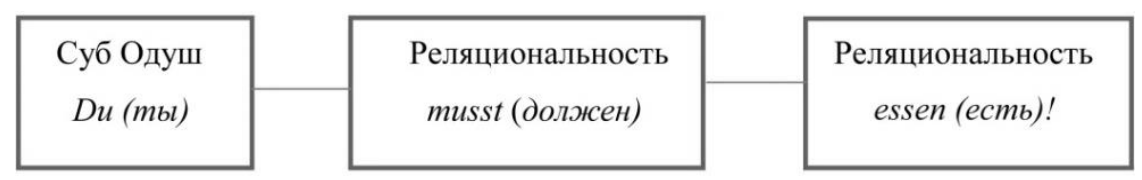

Рисунок 7. Синтагмема линейного предложения

Например, из синтагмем (см. Рисунок 6, Рисунок 7) выводится, что мальчику нужно пойти домой, чтобы поесть, иначе продолжительное голодание может привести к дистрофии. Прагмема всегда связана с побуждением адресата что-то сделать, предпринять. Здесь смысл порождается в контакте между предложениями. В анализируемом тексте смысл бинарен. Из текста вычитывается, что у мальчика стресс, глубокие душевные переживания. Девятилетний мальчик боится не самих крыс, а то, что они съедят тело его брата. Представим вертикальную синтагмему как связующее звено текстемных блоков (см. Рисунок 8).

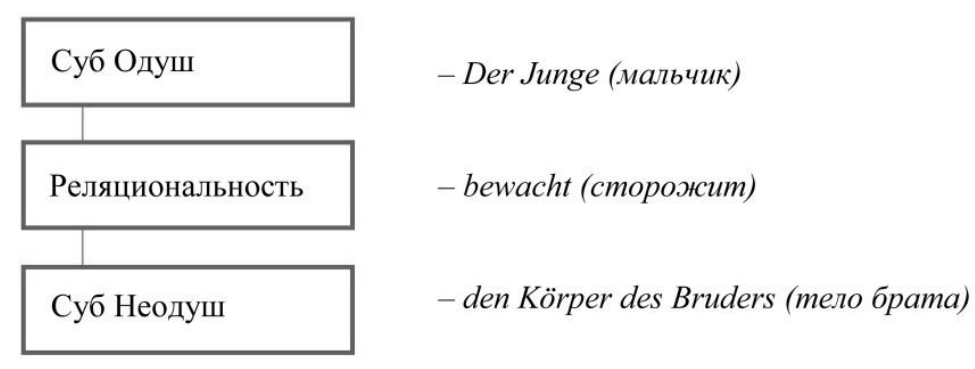

Рисунок 8. Вертикальная синтагмема

В голове мальчика установка, что он должен сторожить тело брата, по этой причине он не может пойти домой. Здесь речь идет о состоянии, отсюда вытекает, что это качество, что мальчик не в себе. В тексте В. Борхерта реципиент вычитывает и более глубокий смысл - осуждение войны, последствия войны. Это позволяет сделать вывод о том, что война у действующего героя рассказа - в голове.

У каждого человека должно быть существо, о котором он должен заботиться. Такой смысл можно вывести из желания мужчины подарить мальчику кролика. Мужчина хочет отвлечь маленького мальчика от мыслей о погибшем брате. С этой целью он выражает свое желание показать отцу мальчика, как построить загон для кроликов. Мальчик как будто оживляется от этой идеи. Об этом свидетельствуют следующие предложения в тексте: “Wir haben Bretter zu Hause”. / «У нас дома есть доски»; “Kistenbretter”. / «Доски от ящика». Он дает мальчику надежду на светлое, может быть и не счастливое, но спокойное будущее. Эту надежду дает автор читателю, оставляя конец своей истории открытым. Действие в тексте происходит вечером. Об этом читатель узнает из самого первого предложения в тексте с темпоральным значением: “Das hohle Fenster in der vereinsamten Mauer gähnte blaurot voll früher Abendsonne”. / «Впалое окно в единственной стене сияло сине-красным светом вечернего солнца», то есть 
близится ночь. И заканчивается действие в рассказе тоже вечером: “Die war schon rot vom Abend...”. / «Beчер окрасил все в красный цвет...». Это значит, что скоро снова выйдут крысы, и, возможно, мальчик будет продолжать оборонять палкой тело своего брата от крыс, не оставит его. Конечно, это не будет являться счастливым концом, но надежду на светлый конец дает квалитативная характеристика автором корма для кроликов: “Grünes Kaninchenfutter, das war etwas grau vom Schutt”. / «Зеленый кроличий корм, немного серый от мусора». Война в рассказе обозначена серым цветом, мрачными красками, кролики были серого, бело-серого окраса, а корм зеленый.

\section{Заключение}

Таким образом, можно сделать выводы о том, что при формировании глубокого коммуникативного смысла текста определяющим фактором является прагмема. Именно прагмема задает тексту основную идею и приводит реципиента к пониманию текста. Следует еще раз отметить, что использование морфотемного анализа в исследовании текста позволило разложить текст на концептуальные синтагмы и парадигмы, выявить связи между ними, которые формируются на основе логосем, и увидеть скрытое авторское намерение. Построение линейных синтагмем позволило сделать вывод о порождении коммуникативных смыслов посредством контактных связей между словами в предложении. Построение и рассмотрение вертикальных синтагмем в качестве связующих звеньев текстемных блоков позволяет сделать вывод о том, что некоторые смыслы порождаются в контакте между предложениями. В этих предложениях на передний план выходят лингвемы, которые при взаимодействии друг с другом превращаются в локутему. Отсюда следует вывод, что смыслы порождаются в межпропозициональном взаимодействии. Таким образом, была достигнута цель данного исследования, то есть была выявлена внутренняя семантическая структура художественных текстов малого жанра (на примере короткого рассказа В. Борхерта “Nachts schlafen die Ratten doch” («Ведь ночью крысы спят»)), а также были выявлены способы смыслопорождения.

Перспективы дальнейшего исследования могут касаться выявления в художественных текстах малого жанра когитемы, то есть элементарной языковой и речевой мыслительной единицы, с учетом имплицитности и эксплицитности репрезентации.

\section{Источники | References}

1. Бабенко Л. Г., Казарин Ю. В. Лингвистический анализ художественного текста. Теория и практика. Учебник. Практикум. М.: Флинта; Наука, 2004.

2. Белянин В. П. Психологическое литературоведение. Текст как отражение внутренних миров автора и читателя: монография. М.: Генезис, 2020.

3. Гальперин И. Р. Текст как объект лингвистического исследования. М.: КомКнига, 2009.

4. Демьянков В. 3. Текст и дискурс как термины и как слова обыденного языка // Язык. Личность. Текст / отв. ред. В. Н. Топоров. М.: Языки славянских культур, 2005.

5. Мурзин Л. Н., Штерн А. С. Текст и его восприятие. Свердловск: Изд-во Урал. ун-та, 1991.

6. Пищальникова В. А. Концептуальный анализ художественного текста: учеб. пособие. Барнаул: Изд-во Алтай. гос. ун-та, 1991.

7. Третьякова И. В. Интерпретация как способ понимания художественного текста // Традиции и новаторство в гуманитарных исследованиях / отв. ред. Ю. М. Трофимова. Саранск: Изд-во Мордов. ун-та, 2002.

8. Фефилов А. И. Введение в когитологию: учеб. пособие. М.: Флинта; Наука, 2010.

9. Фефилов А. И. Диалоги о языке (теория языка для бакалавров и магистров лингвистического профиля): монография. Ульяновск: Изд-во Ульянов. гос. ун-та, 2018.

10. Фефилов А. И. Когитологические аспекты анализа языка в философии и лингвистике: учеб. пособие. Ульяновск: Изд-во Ульянов. гос. ун-та, 2006.

11. Фефилов А. И. Когитология: монография. М.: Флинта, 2017.

12. Borchert W. Nachts schlafen die Ratten doch. Husum: Hamburger Lesehefte Verlag, 2018.

\section{Информация об авторах | Author information}

RU Макаренко Анастасия Сергеевна ${ }^{1}$

${ }^{1}$ Ульяновский государственный университет

EN Makarenko Anastasia Sergeevna ${ }^{1}$

${ }^{1}$ Ulyanovsk State University

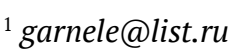

\section{Информация о статье | About this article}

Дата поступления рукописи (received): 08.11.2021; опубликовано (published): 28.12.2021.

Ключевые слова (keywords): когитологическая концепция; логосема; коммуникема; когниция; художественный текст; cogitology concept; logoseme; communiceme; cognition; literary text. 